\title{
OJS OPEN

\section{O ENCONTRO ENTRE GEOGRAFIA E EDUCAÇÃO PODE MUDAR O ESPAÇO VIVIDO?}

\author{
Vanessa Manfio ${ }^{1}$ \\ ${ }^{1}$ Universidade Federal do Rio Grande do Sul, E-mail: vamanfio@hotmail.com, Orcid: https://orcid.org/0000-0002- \\ 0405-5389 \\ Artigo recebido em 18/01/2021 e aceito em 28/04/2021

\section{RESUMO} \\ A Geografia em parceria da educação fornece subsídios para os estudantes aprenderem o seu espaço de vida, \\ por meio de práticas e teorias que ajudam o pensamento crítico, a práxis e a transformação socioespacial. Por \\ isso, é importante trazer à tona essa abordagem para se desenvolver caminhos de uma educação voltada para \\ vida. Esta pesquisa bibliográfica centra-se no objetivo de analisar e discutir a interconexão das duas \\ disciplinas como articuladoras da mudança local, dialogando sobre a pedagogia dos projetos e do trabalho de \\ campo para o ensino. Para pensar uma educação mais rica e interessante que contextualiza o espaço é \\ fundamental no campo escolar, já que o espaço é o chão de aprendizados desde a infância da criança até a \\ sua formação total e permite a criação de um sujeito crítico e humano.
}

Palavras-chave: Educação; Geografia; Espaço vivido; Projetos; Trabalho de campo.

\section{CAN THE ENCOUNTER BETWEEN GEOGRAPHY AND EDUCATION CHANGE THE LIVED SPACE?}

\begin{abstract}
The partnership geography of education provides subsidies for students to learn their living space, through practices and theories that help critical thinking, praxis and socio-spatial transformation. For this reason, it is important to bring this approach to the fore in order to develop life-oriented education paths. This bibliographic research focuses on the objective of analyzing and discussing the interconnection of the two disciplines as articulators of local change, dialoguing on the pedagogy of projects and fieldwork for teaching. To think about a richer and more interesting education that contextualizes the space is fundamental in the school field, since the space is the ground of learning from the child's childhood until his / her total formation and allows the creation of a critical and human subject.
\end{abstract}

Keywords: Education. Geography. Lived space. Projects. Fieldwork. 


\title{
EL ENCUENTRO ENTRE GEOGRAFÍA Y EDUCACIÓN PUEDE CAMBIAR EL ESPACIO DE VIDA?
}

\begin{abstract}
RESUMEN
La asociación geografía de la educación proporciona subsidios para que los estudiantes aprendan su espacio vital, a través de prácticas y teorías que ayudan al pensamiento crítico, la praxis y la transformación socioespacial. Por ello, es importante poner en primer plano este enfoque para desarrollar caminos educativos orientados a la vida. Esta investigación bibliográfica se centra en el objetivo de analizar y discutir la interconexión de las dos disciplinas como articuladores del cambio local, dialogando sobre la pedagogía de proyectos y el trabajo de campo para la docencia. Pensar en una educación más rica e interesante que contextualice el espacio es fundamental en el ámbito escolar, ya que el espacio es la base del aprendizaje desde la niñez del niño hasta su total formación y permite la creación de un sujeto crítico y humano.
\end{abstract}

Palabras llave: Educación. Geografía. Espacio habitado. Proyectos. Trabajo de campo.

\section{INTRODUÇÃO}

A geografia e a educação se encontram ao buscar um entendimento pedagógico e crítico sobre o espaço vivido. Nas palavras de Arroyo, Caldart e Molina (2009, p.14), a escola torna-se um lugar privilegiado de formação, não para fechar-lhes horizontes, mas, para abri-los ao mundo desde o campo, ou desde o chão em que pisam até um mundo mais amplo. Dessa forma, a educação abre possibilidades para se pensar o espaço vivido, as relações cotidianas e as vivências relacionadas à sociedade e à natureza, que é o ponto-chave da geografia, enquanto ciência pedagógica.

Assim, a educação, que privilegia o ensinar o espaço vivido, é um estímulo para que o aluno se encaixe no campo da aprendizagem, e, assim, participe do esquema de visualização da práxis. Neste ponto, a geografia escolar apresenta este horizonte: de trabalhar as questões do conteúdo, a partir de uma gama de práticas e teorias educacionais, a fim de contribuir na transformação da comunidade e da vida do aluno. É fundamental ao aluno aprender e conhecer, fazer e viver em sociedade. Pensando, nesta questão, este artigo procura discutir a relação e a união da geografia e educação para o tratamento do espaço de vivência dos alunos, contribuindo para alternâncias significativas para vida comunitária.

Para dar conta deste objetivo, utilizou-se a pesquisa bibliográfica, como arcabouço metodológico. De acordo com Toledo e Vieira (2011, p. 37), “A pesquisa bibliográfica é aquela que se vale de materiais, como: livros, vídeos, artigos científicos, dissertações ou teses." Ainda, a pesquisa bibliográfica é aquela que tem como referências as informações encontradas em alguns autores, em pesquisas já publicadas, mas, que por uma expressiva revisão de literatura e 
fundamentação teórica dão subsídios ao alcance dos resultados de outras pesquisas (GIL, 2007). Essas pesquisas são importantes, pois permitem "ao investigador a cobertura de uma gama de fenômenos, muito mais ampla do que aquela que poderia pesquisar diretamente" (GIL, 2007, p. 45). Convém frisar que, as fontes bibliográficas foram escolhidas, a partir de trabalhos e autores que desencadeiam uma contribuição à temática, dos quais foram utilizadas: referências no campo da educação e da geografia. Quanto às referências aqui utilizadas destacam-se: Callai (2002 e 2018), Cavalcanti (2002), Freire (1998), Frémont (1976), Gonzáles (2010), Martins (2001), Perrenoud (2002), Pontuschka (1999), Rego (2000 e 2005), Rego e Costela (2019), Straforini (2006), entre outros.

Logo, o presente texto está organizado em três momentos: o primeiro trata da abordagem da união da geografia e da educação no estudo do espaço vivido; o segundo faz uma discussão acerca do trabalho de campo e dos projetos, como ações pedagógicas para se trabalhar o espaço vivido nas aulas de geografia; e o terceiro momento traz as considerações do trabalho. Em suma, com o artigo espera-se contribuir com a temática, que é rica para formação pedagógica dos alunos e da comunidade.

\section{A GEOGRAFIA E A EDUCAÇÃO NO TRATAMENTO DO ESPAÇO VIVIDO}

A união entre Geografia e Educação é um aspecto significativo para se pensar o lugar e o espaço vivido do aluno. Nesse sentido, a Geografia, enquanto disciplina escolar tem a chave para explicar o conceito de espaço vivido e dialogar com a realidade e as experiências locais, construir para cidadania, já a educação tem o caminho para o tratamento dos elementos contidos na Geografia escolar, o modo como ensinar, como produzir conhecimentos pedagógicos e consequentemente formar sujeitos cidadãos. Assim, o encontro entre estas duas ciências é inevitável e ambas são pontes do mesmo caminho para trazer o aluno e o seu ambiente para o centro do debate em sala de aula.

Em um mundo permeado por vários conflitos e dilemas vistos no lugar, nas concretudes do espaço vivido, a possibilidade desse cruzamento entre Geografia e Educação torna-se importante, criando espaço para que as relações sociais se geografizem (REGO, 2000). Confirma Straforini (2006) que a Geografia e a Educação, de uma maneira ou outra buscam o entendimento da realidade, a discussão do espaço e a formação do indivíduo, dessa maneira, elas são complementares entre si. Logo, a união entre estas duas ciências é fundamentada já na 
alfabetização, na escolarização das séries iniciais (STRAFORINI, 2006). Alfabetizar as crianças perpassa de situá-los no espaço e tempo, de dar condições de se relacionarem como o mundo exterior, e, isto é, uma das práticas geográficas, do ato de ensinar geográfica em sala de aula. Para Callai (2002, p. 57),

As séries iniciais, período em que se dá a alfabetização, são o início da vivência socializadora em um grupo formal, organizado fora da criança e por motivos externos à ela. Se o aluno tem de vivenciar a sua vida dentro desse grupo, formalmente desenvolvendo a aprendizagem de certos aspectos da vida, não se pode deixar de lado a vivência que ele tem fora da escola e aquela dos anos de vida que precederam a alfabetização (dentro e especialmente fora da escola).

Neste contexto, a alfabetização necessita do entendimento do cotidiano, das relações e eventos que se processam no mundo vivido do aluno, para se entender tanto o espaço como outros elementos importantes ao desenvolvimento intelectual e cognitivo do aluno. Esta abordagem, do espaço vivido e cotidiano, então, pode ser "o pano de fundo que embasa todo este processo de iniciação escolar, que tem como fundamental a alfabetização" (CALLAI, 2003, p.77). Completando ainda que ao estudar o lugar é possível compreender o mundo (CALLAI, 2010). Além disso, a criança aprende por meio do afetivo, do processo mental que se cria com o fundamento do ser e estar no mundo. Então, quando se usa o espaço vivido para ensinar e educar fundamenta-se o esperançar e a necessidade do aluno de compreender o que está em sua volta e o despertar para educação. Em Santos (1996), a vida não é fria, desconexa e não pode ser vivida simplesmente pela razão, já que a emoção dá sentido ao olhar e entender o mundo e as coisas por uma ótica mais humana. Com isto, a geografia escolar tem tudo a ver com a vida do educando (CALLAI, 2018), e por meio dessa noção se põe em evidência também a leitura, as operações matemáticas, a biologia, a arte e as ciências sociais.

Com isto, o espaço é uma categoria que permite a exploração de um grande universo. Para Cavalcanti (2002, p.19), “o espaço geográfico não é apenas uma categoria teórica que serve para pensar e analisar cientificamente a realidade; ele é uma categoria justamente porque é algo vivido por nós e resultante de nossas ações”. Então, explorar em sala de aula o espaço vivido é tratar o jogo das relações e acontecimentos deste, analisando o espaço social e o trabalho da sociedade na transformação espacial, na hidridação das coisas e das relações hierarquizadas dentro da fronteira do saber e do pensar/experienciar (FRÉMONT, 1980). Dessa forma, por meio do espaço vivido pode-se trabalhar os movimentos sociais, o poder e a territorialização, as questões ambientais, econômicas e culturais e, sobretudo, os diferentes espaços, o urbano e rural, o natural e o material/humanizado, os acontecimentos do jornal, da internet, do dia-a-dia do aluno e para tanto 
contribuir com o engajamento do mesmo nas questões ligadas à sua vida e da sua comunidade, bem como a transformação do seu espaço com ações extencionistas.

Destarte, a educação forma pessoas para o exercício da cidadania, bem como a geografia participa desta formação quando ensinar conceitos de espaço, lugar, sociedade, cidade, meio ambiente. A pedagogia oferece o suporte a partir de teorias e métodos, tais quais aplicação de projetos, metodologias ativas, formas de avaliação, de ensino pela práxis. Assim, a escola como um todo oportuniza aos alunos as ferramentas intelectuais para atuar na sociedade, na vida e ser sujeito que vive e que possui direitos e deveres no presente, e que também é ator em construir o futuro (CALLAI, 2018). Porém, estes fundamentos educacionais somente se evidenciam quando se utiliza o lugar, do espaço vivido e a noção de geografia, visão de mundo e do cotidiano. Então, a escola é um local que possibilita a vivência social, diferente da do grupo familiar; ela compensa carências do aluno, oferecendo-lhe oportunidades de acesso a informações e experiências novas e desafiadoras, é espaço de provocações e de desencadear processos de desenvolvimento e comportamento (REGO, 2005). A escola muitas vezes é espaço de afetividade, de suprir perdas emocionais e sociais, de criar sujeitos afetivos e participativos. Mas, também é o espaço de construir sujeitos críticos e sociais. Então, tanto a pedagogia como a geografia se alinham para fornecer conhecimentos aos educandos sobre política, meio ambiente, sociedade, desigualdades sociais. Estes elementos são importantes para uma consciência cidadã. Nesta visão Kaercher (2003, p. 174) afirma,

Compreender as desigualdades sociais e espaciais é uma das grandes tarefas dos professores de Geografia para que a nossa ciência instrumentalize as pessoas uma leitura mais crítica e menos ingênua do mundo, que desemboque numa maior participação política dos cidadãos a fim de que possamos ajudar a construir um espaço mais justo e um homem mais solidário [...].

Assim, a relação da escola com a realidade social é bem dinâmica, possibilitando a luta por melhores condições de vida, o surgimento de líderes políticos e representantes das classes populares, a desmistificação dos conteúdos das matérias, contribuindo, para o senso crítico e social do sujeito que se deixa educar (SOARES, et. al., 2012). Contudo, com a educação há a esperança de uma sociedade melhor no futuro, caracterizando-se por ser um caminho para educar e conscientizar a sociedade, para mudança de postura com o meio ambiente e entre os sujeitos da sociedade, logo, ensinar geograficamente permite tornar os alunos agentes desta mudança (ROHDE, 2012).

Dentro da geografia escolar, o conceito de espaço é tido como principal, a partir dele há uma relação com outros conceitos e assuntos da ciência e de outras disciplinas. E o espaço visto pela ótica do vivido se materializa no ensino. Em Frémont “O espaço vivido é um espaço-movimento e 
um espaço tempo vivido" (1976, p. 33). Ele demonstra história, crenças, relações, cultura, repleto de impressões e sentimentos, sendo o espaço, contudo, o local onde a vida acontece plenamente (FRÉMONT, 1976). Por isso, ele suplanta o ensino da pedagogia e da geografia. Conforme Pontuschka (1999, p.133): “As condições de existência dos próprios alunos e seus familiares são pontos de partida e de sustentação que podem garantir a compreensão do espaço geográfico dentro de um processo que vai do particular ao geral e retorna enriquecido ao particular". Contudo, o entendimento espacial deve favorecer a criatividade dos alunos, no sentido de observar, pesquisar, entender e perceber o mesmo. Evidente que não é uma tarefa fácil despertar neste domínio nos estudantes. Com isto, a tarefa da escola e do professor é dialogar este assunto, tendo ênfase na necessidade de promover experiências que garantam o desenvolvimento do assunto em sala de aula, e também produza a capacidade de criticidade do aluno (SANTANA, 2015), isto é, através de metodologias participativas.

$\mathrm{Na}$ vida, os indivíduos são levados a querer conhecer lugares longínquos e recuados do cotidiano, levando-nos a subjugar os acontecimentos e as demandas do lugar em que vivemos, o que os torna pouco conhecedor do ambiente no qual estão inseridos e fazem parte (CALLAI, 2004). Conhecer o lugar de vivência é importante para se criar sujeitos comprometidos com o ambiente e sociedade, criar a tal de cidadania e os domínios da educação ambiental e social. É conhecer a história de si mesmo, já que o espaço é dotado de seres e estes são parte do mesmo. O ser humano deve estar engajado com o seu entorno isto é educação, e também é ensino de geografia. Porque a geografia está em toda parte, no dia-a-dia e nos acontecimentos banais como passear, trabalhar, relacionar-se (KAERCHER, 1999; CROSGROVE, 1998).

Logo, “A ciência geográfica aplicada às séries iniciais deve permitir que o aluno se perceba como participante do espaço em que estuda, em que os fenômenos que ali ocorrem são resultados da vida e do trabalho dos homens" (SANTOS, 2007-2008, p.97). O lugar e o espaço vivido são, portanto, categoria básica do ensino fundamental, ou seja, é o chão, para se construir novos conhecimentos e conteúdos. Partindo desse pressuposto, o estudo do espaço vivido torna-se uma alternativa metodológica do ensino, em que ganham destaque a observação, a representação, a compreensão, a avaliação e a intervenção em processos geográficos (SANTOS, 2007-2008). Ainda, o espaço vivido é ponto de partida do aluno, assim é por meio desta categoria que o educando tem maior grau de compreensão e de abstração para decifrar a paisagem, e os demais conceitos geográficos e educativos. Contudo, saber olhar o espaço vivido através das experiências, por as 
atividades associadas ao cotidiano, torna-se significativo para o processo de ensino-aprendizagem (SANTOS, 2007-2008).

Por conseguinte, a educação favorece uma gama de metas, de lições que formaram para vida, que garantem fronteiras impermeáveis para produção do ser humano (REGO; COSTELA, 2019). A geografia educativa precisa se inserir na vida do aluno, no lugar do encontro da criança com o mundo, não apenas tratar de temas relevantes, dar sentido ao que de fato importa dentro do saber escolar e social. Para Gonzáles (2010), se não incluir-se na educação problemas da sociedade, da escala local, se o ensino não responder as respostas que os estudantes têm sobre o mundo, que começa na sua casa, no seu bairro, cidade e se estende a outros patamares não conseguirá desenvolver um olhar geográfico e educativo. Nem um ensino vibra com a realidade imaterial, abstrata e não coerente aos olhos do seu público, pois a final de contas só se aprende quando se tem vontade, quando se desejar descobrir, pesquisar e ler o mundo. E isso somente acontece quando se visualiza no lugar a existência das possibilidades de encontro entre educação, geografia e conhecimento.

Numa outra colocação, "O lugar, espaço vivido, é um espaço entremeado pela cultura e com o qual relações afetivas são estabelecidas" (BRAZ, 2015, p.126). Estas relações afetivas e culturais estão embutidas no espaço escolar, através de várias representações e símbolos que devem ser contextualizados em sala, a fim de criar um pensamento reflexivo sobre a diversidade e a identidade cultural, o que agrega um posicionamento pedagógico (BRAZ, 2015). Isto ajuda a pensar a diversidade dentro do espaço, ampliando o entendimento do educando para o diferente, ou para o diverso, onde nem todos os alunos têm a mesma característica étnica, tão pouco costumes e hábitos, mas eles habitam um espaço que é de todos. Desse modo, o espaço deve ser entendido e pensado como campo existência, de relações, distâncias, tamanhos, extensos e diversidades, diferenças e relatividades (MOTTA, 2003).

Nesta visão, educar geograficamente consiste em "problematizar o que não é visto como problema e desproblematizar o que é visto somente como problema, além de ressignificar vivências, ressignificamos lugares" (REGO; COSTELA, 2019, p. 10). Os autores comentam que propor aos alunos a reflexão sobre os idosos no seu local de vivência ajuda a discutir os temas de juízo da velhice, forma pessoas capazes de se socializar com os direitos e deveres desde grupo social, mas abre leque para se discutir população, qualidade de vida, entre outras temáticas que além de ser educativas são geográficas. Se os alunos conseguem entender a lição do reciclar, do lixo como um fator de questão social e ambiental estará-se-ar educando para vida, mas também na perspectiva 
geográfica de educar para preservação do meio ambiente. Isto é problematizar o que é visto pelo aluno e desproblematizar buscando novas experiências e vivências, um mundo mais equilibrado e social.

Em Rego (2000), o autor aborda o conceito de geração de ambiências como um conjunto de aspectos comuns envolvendo expressões, práticas e esforços de educadores em âmbitos formais e não formais para melhoria das condições associadas aos locais de vivência. Na elaboração do conceito foram apontados três vetores: eleger aspectos do vivido, dialogar as interpretações dos participantes e a instauração do próprio ambiente dialógico (REGO, 2010). E por meio deste conceito seria possível tratar com os estudantes assuntos do meio. Reintegrando que a educação deve socializar para a transformação da realidade e meio dos estudantes.

Como o ensino geográfico deve ser pautado na realidade, exige-se do docente uma postura que crie condições para isto. Conforme destaca Moro (2016, p.9):

A Geografia, em sua dimensão social de análise do espaço geográfico deve proporcionar ao aluno uma aprendizagem mediada pela realidade dos mesmos. Assim, o ensino atual está a exigir dos professores de geografia uma nova postura pedagógica, em que o conhecimento seja mediado pelo diálogo entre o que aprende e o que ensina, entre a análise local e global, bem como entre o saber popular e o saber científico.

Assim, educação e geografia andam de braços dados para ensinar e formar pessoas, a mostrar que o espaço vivido e o cotidiano merecem atenção e são o esboço para a compreensão da problemática global. Logo, “O ambiente escolar educa ao mesmo tempo em que ensina. O oculto nas filosofias escolares se faz visível e atuante na vida dos alunos fora da escola e para além dos anos escolares" (REGO; COSTELA, 2019, p.11). Ensinar não é transmitir conteúdos prontos, mas criar possibilidades de diálogo entre saber científico e saber empírico, entre teoria e prática, entre o mundo abstrato e real. Não existe ensino se o mundo não couber nas mãos dos alunos (REGO, et. al., 2000). E assim todo ensino, inclusive de geografia, imbrica-se na educação, na formação do humano (REGO; COSTELA, 2019).

A ciência geográfica apresenta no seu campo de conhecimento e responsabilidade, um conjunto de saberes fundamentais para a formação das crianças, dos adolescentes e dos jovens, por isso, as práticas escolares devem possibilitar que esses saberes sejam materializados no âmbito da extensão e tratamento científico (THIESEN, 2011). Diante disso, trabalhar a rua, o bairro a cidade em múltiplas vertentes, assuntos, dilemas e fazê-los pensar sobre os temas, bem como contribuir com a noção de como melhorar ou transformar o lugar é fundamental para que a geografia 
educativa se concretize como uma disciplina escolar com caráter dinâmico, colaborativo e de extensão prática.

Por último, a geografia tanto, enquanto disciplina científica (que pesquisa elementos, que cria ferramentas para analisar sociedade e meio e que se vincula ao universo acadêmico), quanto à geografia que se ensina nas escolas (no ensino básico, reportando o pensamento geográfico), são integrantes da mesma ciência, e elas educam para preservação do meio ambiente, para o pensamento social e para o estudo do espaço vivido.

\section{CONTRIBUIÇÕES DA GEOGRAFIA E EDUCAÇÃO NO ESTUDO DO ESPAÇO VIVIDO: PROJETO E TRABALHO DE CAMPO NESTE RUMO}

Sabe-se que a geografia e a educação são parceiras na construção do ensino básico do aluno. Até porque não existe ensino sem pedagogia. Mas, de que maneira elas podem trabalhar juntas em sala de aula?. A atuação de projetos educativos pode ser um ponto fundamental nesta concepção, de inserir os alunos na problemática local e do cotidiano. Além disso, inserir o cinema, a literatura, as histórias, mapas mentais, trabalho de campo e memórias auxiliam a educação dos alunos neste rumo. Contudo, neste item será tratada à questão dos projetos e do trabalho de campo, exclusivamente como elos para uma educação geografia para o espaço vivido, compreendendo-os como metodologias ativas ou participativas.

Nesta perspectiva, as metodologias participativas, onde o aluno passa aprender ativamente são significativas e merecem o olhar do docente. Estas metodologias auxiliam no interesse dos alunos e na sua socialização com o mundo vivido. Como menciona Braz (2015, p.131), "tais metodologias propõem questionamentos e o desenvolvimento da temática a partir dos elementos colocados pelos próprios estudantes". Para Castellar (2011) é importante para os educandos serem instigados à aprendizagem por meio de atividades que lhe garantem à participação, a fim de obterem maior aproximação entre a ciência e o cotidiano. Pois, o ensino - aprendizado é constante e dinâmico, um processo que vai se construindo diariamente, por meio de ações contínuas e entrelaçadas a realidade extra-escolar.

Diante disso, os projetos são importantes, pois são ferramentas de metodologia participativa, ativa e também porque podem ser aplicados junto com a comunidade e isto leva a transformação do espaço vivido. Projetos de hortas urbanas, de educação ambiental, de transformação e análise da paisagem, são fundamentados no estudo do espaço vivido para além da teoria e sim para mudança 
espacial e social. Neste caso, situações de aprendizado que envolva a compreensão da morfodinâmica e o manejo de solos, relevo, recursos hídricos e a recursividade entre humano, flora e fauna, entre outras, em parceria com outras relações sinalizam práticas participativas e individuais (REGO, 2010). Estas situações geralmente são protagonizadas por projetos de intervenção e/ou ensino podem ampliar o grau de pertencimento dos alunos e possibilitar ações comunitárias. Quando o aluno sente-se pertencer ao espaço que vive com certeza terá mais consciência ambiental, mais interesse em participar de ações e melhorias da rua, do bairro e da cidade e de lutar por estas. A educação e a geografia precisam mostrar o papel do estudante no seu meio e a sua força, bem como suas ações interferem para o bem ou mal na sociedade/espaço.

Por outro lado, o ensino por meio de projetos leva a construção de conhecimentos (com uma atitude indagadora, que identificar problemas, e constrói conceitos, processando informações), além de uma prática continua de aprender a aprender e uma prática do trabalho coletivo, cujos educandos lidam com a tomada de decisões acerca da realidade pesquisada e da apresentação dos resultados de investigação (CAVALCANTI, 2002). Logo, Prado (2005) ressalta que, "Na pedagogia de projetos, o aluno aprende no processo de produzir, de levantar dúvidas, de pesquisar e de criar relações, que incentivam novas buscas, descobertas, compreensões e reconstruções de conhecimento". Assim, Martins (2001 p. 20) escreve que "por meio dos projetos de pesquisa os alunos estariam, [...], tendo contato e redescobrindo o conhecimento científico, adaptando-os ao conhecimento do senso comum e com eles poderiam esclarecer, explicando os fatos e os problemas estudados". Os alunos têm, então, a oportunidade de descoberta e de aprendizado social, didático e real, de se tornar o protagonista no processo de ensino - aprendizagem.

Em Demo (2002), a pesquisa, através de projetos escolares, é uma forma de fazer do aluno o autor, com idéias próprias, com capacidade de argumentar com autonomia, de entrar em discussão e de propor projetos próprios. Porém, é necessário mais que projetos teóricos, e sim projetos que se utilizam de prática de mudança social. Como destaca Demo (2002, p.94), "é de todo prudente promover pesquisas que exijam mais que dedicação teórica, também para cultivar a capacidade de agir, não só de pensar". Destarte, a pesquisa pode situar o aluno em suas potencialidades, bem como em suas fragilidades, impondo a ele próprio a necessidade de superação das fragilidades, a correção de erros, a escolha de caminhos, mantendo a autovisualização de possibilidades (SILVA, 2011, p.29).

Colaborando com o exposto, Martins (2001), afirma que os projetos de pesquisa são propostas pedagógicas, por vezes interdisciplinares, abrangendo atividades orientadas pelo 
professor, destinadas a promover situações de aprendizagem dinâmicas e efetivas. Frisa ainda Perrenoud (2002), que o trabalho com projetos como uma proposta metodológica possibilita o desenvolvimento de competências, dos quais para o projeto existir é necessário à participação efetiva do professor e do aluno em cada etapa do processo, sendo essa ação a de construção vivenciada. Havendo uma troca entre docente e aluno, entre alunos, entre comunidade e escola, construída simultaneamente, e que pode abranger apenas uma disciplina ou várias. Nas palavras de Almeida (2002, p. 58),

[...] o projeto rompe com as fronteiras disciplinares, tornando-as permeáveis na ação de articular diferentes áreas de conhecimento, mobilizadas na investigação de problemáticas e situações da realidade. Isso não significa abandonar as disciplinas, mas integrá-las no desenvolvimento das investigações, aprofundando-as verticalmente em sua própria identidade, ao mesmo tempo em que estabelecem articulações horizontais numa relação de reciprocidade entre elas, a qual tem como pano de fundo a unicidade do conhecimento em construção.

Portanto, Hernández (1988, apud PRADO, 2005) o trabalho educativo por meio de projeto não deve ser compreendido como uma opção metodológica de ensino, mas como uma maneira de repensar a função da escola. Avaliando a escola como mecanismo para educar para vida, para transformar a sociedade e o meio, o entorno, algo socializador com a comunidade escolar, aberta ao diálogo e as necessidades comunitárias, e não apenas como reprodutora de conteúdos. Nesse sentido, Prado (2001) acrescenta que os projetos educativos direcionados pelo docente possibilitam ao aluno saltar de passivo para ativo, pois o discente terá que percorrer uma trajetória, elaborar estratégias e equipe, juntar e analisar informações, contribuindo para que a aprendizagem seja significativa.

Ao realizar uma varredura destes projetos pelas plataformas de divulgação científica encontraram-se projetos variados com a ênfase de educar para o conhecimento do espaço vivido e mudança do mesmo, em parceria de escolas e universidades de todo Brasil, envolvendo apenas a geografia ou a interdisciplinaridade, com temas complexos e diversificados que promovem uma valorização de memórias, do meio ambiente, da cultura, da cidade, etc. Projetos que visualizam a mudança do aluno como ser social, porém para isto "é preciso uma reeducação individual e coletiva que implica em uma reorientação sobre a visão de mundo, sobre a inserção do indivíduo neste mundo e sobre sua responsabilidade para com o mesmo" (SPRINGER; SOARES, 2008, p.791). Muitos projetos buscam amenizar os quadros de vulnerabilidade social e fragmentação do espaço vivido pelas comunidades escolares. 
Convém ressaltar que a pesquisa na Escola de Educação Básica é um processo diferente do puramente ensinar, não se confundindo com os rotineiros trabalhos propostos, ou melhor, impostos pelo professor como tarefa de casa (SILVA, 2011). Mas, de uma pesquisa que tenha fases e normas, dos quais os alunos precisam seguir parâmetros e ter limites, sendo então possível desenvolver deste as séries iniciais até o ensino superior o hábito e gosto por pesquisar (SILVA, 2011). Propor pesquisas é levantar problemáticas e fazer os alunos resolvê-las, buscando a socialização e o conhecimento, compartilhando de saberes e trazendo contribuições a comunidade escolar.

A metodologia de ensinar geografia do espaço vivido por meio de projetos ganha ênfase agora no Ensino Remoto Emergencial (ERE), onde o aluno precisa aprender de forma mais autônoma. Na pandemia do COVID-19 as escolas têm se adaptado a ensinar de forma diferente, sem o presencial, e a metodologia por projetos consiste numa ferramenta para dar conta desta amarra ao promover o domínio do aluno em construir o seu conhecimento, a partir de projetos criativos, de um olhar curioso e atento sobre os conteúdos. Para Rêda (2006), a implementação de uma metodologia inovadora que se utiliza de um projeto de ensino é fundamental para conceber e organizar as ações e atividades a serem desenvolvidas pelos alunos. É onde os alunos podem construir o seu aprendizado, guiado pelos docentes.

Desse modo, a "Metodologia de Projetos não é compatível com a transmissão de conteúdos preestabelecidos, descontextualizados da realidade e das vivências dos alunos" (GANDIN, 2001, p. 43). A pedagogia de projetos tem sua origem associada aos trabalhos de John Dewey (1916) e William Kilpatrick (1918), sendo empregada na educação, especialmente no movimento da Escola Nova, compondo uma pedagogia progressista, também chamada de pedagogia aberta, cujo aluno se tornava ator de sua formação através de aprendizagens concretas e significativas para ele (BOUTINET, 2002). Logo, a metodologia de projetos se baseia em estudar a realidade e o espaço vivido para dar suporte ao aluno aprender e conhecer o seu mundo, buscando que o mesmo trabalhe na realidade e possa interferir nela também.

Por outro lado, a metodologia de ensino por projetos tem como finalidade contemplar as aprendizagens que se baseiam no aprender a conhecer, aprender a fazer, aprender a ser, aprender a conviver (DELORS, 1998). Nesse sentido, o aluno pode interrelacionar com outros colegas e sujeitos, pode relacionar teoria e prática, pode participar da sociedade como sujeito social, pois educa para a construção da cidadania, para o vínculo com o meio e a sociedade. Isto é, ajuda a explorar os talentos escondidos no interior de cada ser humano, tais quais: a memória, o raciocínio, a imaginação, as capacidades físicas, o sentido estético, facilitando também o ato de comunicação 
com os outros (DELORS, 1998). É mais que ensinar conceitos prontos e acabados, é orientar o aluno para responder questões reais e construir sujeitos, valorizando suas habilidades e capacidades.

Neste ponto, os projetos podem desenvolver trabalhos artísticos, de educação ambiental e de práxis. Os projetos podem ser simples ou mais complexos. Os complexos são aqueles que se beneficiam de um tempo mais longo, um conteúdo organizado de forma a abranger o vivido e o teórico. Os projetos mais simples podem ocorrer no entrosamento da sala de aula, adentrando algumas aulas, já os complexos rompem com o limiar da escola.

Diante do exposto, Oliveira (2006), afirma que o ensino por meio de projetos rompe com o conceito de teoria com um conhecimento especulativo, racional, associada a métodos e técnicas, de um ensino mecânico e desconectado do que o aluno quer aprender e da sua vida. A metodologia por projetos articula teoria e prática e em muitos casos dá sentido ao que se ensina e para que se ensina, já que faz o aluno estar no campo do conhecimentos, aprender por conta própria e de forma clara e concisa, uma aprendizado para sempre.

Para Leite (2007), o aluno quando participa de uma metodologia de ensino por projetos adentra numa experiência educativa, dos quais o processo de construção e reconstrução do conhecimento está integrado às práticas vivenciadas, representando um ganho para o mesmo e para a educação como um todo. $\mathrm{O}$ aluno é inventariante do conhecimento e da competência de formulação objetivos, responder questões e desvincular do óbvio para encontrar fundamento do que é estudado.

Além dos projetos, o trabalho de campo é um meio muito utilizado para trabalhar o espaço vivido do aluno na busca de contribuir com um processo educativo permanente e ativo. Nas palavras de Freire (1998, p.32) "Não há ensino sem pesquisa e pesquisa sem ensino. (...) Pesquiso para conhecer o que ainda não conheço e comunicar ou anunciar a novidade". A metodologia de trabalho de campo tem como instrumento fundamental a observação, já que a partir dessa e das reflexões que ela permite emerge-se a consciência social e ambiental, bem como uma postura que compreende a relação de interdependência entre os organismos (ALMEIDA, 2013). Segundo $\operatorname{Marcos}(2006$, p.6):

Penso que a maior parte dos geógrafos concorde com o fato de que a ida a campo seja um instrumento didático e de pesquisa de fundamental importância para o ensino e pesquisa da/na Geografia. Enquanto recurso didático, o trabalho de campo é o momento em que podemos visualizar tudo o que foi discutido em sala de aula, em que teoria se torna realidade, se 'materializa' diante dos olhos estarrecidos dos estudantes, [...]. 
No trabalho de campo se põe a mostra e se compara in loco os conhecimentos prévios e os internacionalizados em sala de aula, observando o espaço vivido e experienciado. Conforme Azambuja (2012, p.188), “Na Geografia o olhar vai além, o meio geográfico em estudo é então fonte de pesquisa por meio do trabalho de campo escolar". Desse modo Lopes e Pontuschka (2010, p. 30),

[...], durante o trabalho de campo, educadores e educando devem submergir no cotidiano do espaço a ser pesquisado, buscando estabelecer um rico diálogo com o espaço e, na condição de pesquisadores, com eles mesmos. É o momento de descobrir que o meio ou o espaço, na interrelação de processos naturais e sociais, é uma Geografia viva.

Destarte, o Trabalho de Campo serve de estímulo, pois utiliza situações concretas, sugerindo uma aplicabilidade imediata do conteúdo, propicia descrição, comparação, explicação e a compreensão dos diversos elementos geográficos presentes no espaço vivido (CASTROGIOVANNI, 1984). Por meio do campo leva-se o aluno a descobrir o que os professores já sabem, levando-o a pensar o espaço, onde o estudante pode-se descobrir como um elemento atuante e, dessa participação, assumir a responsabilidade de ser um ser transformador deste espaço (CASTROGIOVANNI, 1984).

Neste contexto, a aula em campo permite que o estudante aprenda os conteúdos com mais facilidade, mesmo até aqueles de difícil domínio intelectual podem ser compreendidos por meio da exploração do meio e da interlocução com este que pode gerar melhorias ao espaço e comunidade onde a tarefa de campo acontece. Como explora Fontana e Cruz (1997), o trabalho de campo representa uma possibilidade de contato direto entre pesquisador ou aluno e a realidade estudada, o que permite a apreensão dos aspectos dificilmente vislumbrados através de uma aula expositiva ou de uma pesquisa bibliográfica. Doravante, o trabalho de campo, pode (re) significar os conteúdos e as aprendizagens a partir da conexão entre conhecimentos e o cotidiano (CIOCCARI, 2013). Ressalta ainda Cioccari (2013, p.39) que no trabalho e campo "o aluno é visto como indivíduo único, que constitui e é constituído como sujeito da história, ou seja, é um ser inerente ao fato, ao processo de ação, e se torna, juntamente com a sua comunidade, um elemento transformador do sistema social, que espacializa suas relações”.

Essa metodologia que abarca o trabalho de campo demonstra para os educandos o quanto à Geografia se faz presente no cotidiano, permitindo com que esses estudantes conheçam as relações que estão a sua volta, favorecendo a criação de um sentimento de pertencimento com o local e com o processo de constituição espacial (PAIVA; OLIVEIRA, 2018). É uma metodologia que rompe com o ensino tradicional (CASTROGIOVANNI, 2015). Daquele ensino que coloca conceitos 
prontos e acabados para os alunos memorizar como uma verdade concebida e sem distinção de espaços e escalas. Pois, no espaço vivido nem sempre a teoria pode ser assumida como uma verdade absoluta, por exemplo, é possível dizer que a cidade é o encontro do movimento, das formas, do agito, das construções e concreto, porém quando se trata de uma pequena cidade interiorana, nem sempre estas condições são tão claras e nítidas, porque são percebidas num outro ponto de vista e, às vezes, camufladas pela confluência local, pelo contato direto com o rural e com o patamar populacional.

Em momentos de distanciamento social, a utilização do trabalho de campo está comprometida, os campos partem mais do contato virtual, de visitas e entrevistas on-line, que para o aluno de ensino básico, às vezes é mais desafiante, sendo neste ponto, a metodologia por projetos mais rica e didática.

Evidente que, tanto o projeto como o trabalho de campo puramente devem ser bem planejados e conduzidos para que eles tragam contribuições para os alunos e para a comunidade em geral. Não é levar os estudantes passear, mas fazê-los observar e aprender sobre a sua realidade ou a do outro. O projeto e o trabalho de campo podem ser parte de uma mesma proposta pedagógica, pois na pesquisa também se faz com trabalho de campo, principalmente quando se lida com realidades e ambiências no campo do saber.

Diante do exposto, tanto os projetos quanto o trabalho de campo são formas pedagógicas que unem educação e geografia no ensino-aprendizado, principalmente quando o assunto trata do espaço vivido do alunado e os impulsionam a serem sujeitos ativos no seu meio, auxiliando na transformação de postura, ideias e realidades de vida. Como mencionam Rossato e Suertegaray (2014, p.60), "Ensinar exige coragem de ousar em atitudes que valorizem o educando como indivíduo repleto de experiências de vida, com curiosidade sobre o mundo em que vive, capacidade criativa e com potencial para despertar um olhar inquieto sobre a vida". Educar, então, parte de ensinamentos contextualizados com a vida, com o espaço e com a interdisciplinaridade de temas, ciências e pedagogias. A educação em consonância com a geografia dá visibilidade ao que alimenta os alunos, ou seja, o seu espaço e a sua vida, transformando lugares, espaços, pessoas e comunidades, porque a educação que se insere no seio do espaço dos alunos é a da práxis e tem um víeis de mudança e de permanência do ensino. 


\section{PARA NÃO FINALIZAR}

A educação e a geografia são páginas de um mesmo livro, juntas conseguem transformar o estudante, que deixa de ser apenas aluno e se torna sujeito crítico e social, com uma visão empírica respeitada e que tem responsabilidades, principalmente no seu espaço vivido. Educar supõe criar conhecimentos e seres, não apenas fazer os alunos reproduzirem conhecimentos, mas relacionar os conteúdos na sua prática, vistos na ousadia do seu dia - a - dia.

Esta oportunidade é nítida no ensino de geografia que se relaciona com o espaço vivido, com o cotidiano e com o espaço do aluno. Desde criança aprende-se no mundo de vivência, e este aprendizado vai adquirindo novas fronteiras, mas deve ser sempre associado ao lugar, a fim de não se perder o interesse e tão pouco o contato direto com a geografia da vivência. Ou seja, tudo pode se transformar numa aula de geografia, assim como essa disciplina caminha para o extra - escolar na medida em que se localiza no espaço, se lê a paisagem, se preserva o meio ambiente e se transforma a sociedade.

Nesta união entre educação e geografia nasce a necessidade de promover mudanças ao espaço vivido, mas para que isto aconteça são fundamentais caminhos largos e longos, vistos por práticas pedagógicas que unam sala de aula e extensão, como a metodologia de projetos e o trabalho de campo. Tanto um quanto o outro se utilizam da observação e da tentativa de mudança de postura, colocando o aluno no centro do ensino-aprendizagem e fazendo-o pensar, propor e mudar o seu espaço vivido seja no campo das ideias, ou seja, no das ações. Assim, os professores mediadores desse processo ajudarão na instrumentalização do saber e das ações, instigando os alunos e a comunidade escolar em melhorias e diálogos com o que pode ser mais que fundamentado ou vulnerável transformando em cortinas para a sustentabilidade em placo e para o autoconhecimento do espaço vivido.

Afinal, educar e ensinar geograficamente para compor apenas conhecimentos soltos e textos bem escritos, não tem sentido se não educarmos para o pôr em prática, para cidadania, para preservação e relação social. Se a educação não transformar o mundo de nada adianta ensinar. Serão apenas mais letrinhas desconectas da realidade, mais estudantes dotados de saberes sem condições de transpor para sua vida o que é vistos na escola. Cada vez mais, conhecimentos são adquiridos em todos os espaços e momentos, mas a educação e a geografia neste encontro têm a visão de transformar o espaço e o sujeito em diversos sentidos. Em suma, o mundo fora da escola é repleto 
de acontecimentos e entendê-los se faz necessário para vida, para o trabalho e para estar-se e atuar no mundo não como coadjuvante, mas como ator principal.

\section{REFERÊNCIAS}

ALMEIDA, M. E. B. de. Como se trabalhar com projetos (Entrevista). Revista TV ESCOLA. Secretaria de Educação a Distância. Brasília: Ministério da Educação, SEED, n. 22, mar./abr. 2002.

ALMEIDA, D. S. A importância do trabalho de campo no estudo da geografia. 2013. Disponível em http://www.brasilescola.com/geografia/trabalho-de-campo-no-estudodageografia.htm. Acessado em 14.Out.2020.

Arroyo, M. G.; CAldart, R. S.; MOLINA, M. C. Por uma Educação do Campo. 4.ed. Rio de Janeiro: Vozes, 2009. 214p.

AZAMBUJA, L. D. Trabalho de campo e ensino de Geografia. Geosul, Florianópolis, v. 27, n. 54, p 181-195, jul./dez. 2012.

DELORS, J. (Coord.). Educação: um tesouro a se descobrir. Relatório para Unesco da Comissão Internacional sobre Educação para o Século XXI. São Paulo: Cortez, Unesco, 1998.

BRAZ, R. L. De Onde Parte o Ensino Escolar da Geografia: Considerações acerca da relação Espaço Vivido e Ensino-Aprendizagem. Geografia, Londrina, v. 24, n. 1. p. 125 - 132, jan/jun, 2015.

BOUTINET, J. P. Antropologia do projeto. Porto Alegre: Artmed, 2002.

CALLAI, H. C. O ensino em Estudos Sociais. 2ª ed. Ijuí: Unijuí, 2002.

CALLAI, H. C. O estudo do município ou a Geografia nas séries iniciais. In: CASTROGIOVANNI, A. C., et al. Geografia em sala de aula: práticas e reflexões. $4^{\mathrm{a}}$ ed. Porto Alegre: UFRGS, 2003.

O Lugar como possibilidade de construção de identidade e pertencimento. Artigo apresentado no VII Congresso Luso-Afro-brasileiro de Ciências Sociais. Anais... Coimbra, 2004. http://www.ces.uc.pt/lab2004/pdfs/HelenaCallai.pdf. Acesso em 30/04/2020.

. Educação geográfica para a formação cidadã. Revista de Geografia, Norte Grande, n.70, Santiago, set. 2018.

CASTELlaR, S. M. V. Jogos e Resolução de Problemas Para o Entendimento do Espaço Geográfico no Ensino de Geografia. In: Educações Geográficas Reflexão Prática. Rio Grande do Sul, 2011.

CASTROGIOVANNI, A. C. Trabalho de campo no ensino da geografia na escola de $1^{\circ}$ e $2^{\circ}$ graus. Boletim Gaúcho de Geografia, Porto Alegre, v.12, p. 71-74, maio, 1984. 
CASTROGIOVANNI, A. C. Movimentos dentro e fora da sala de aula: o trabalho de campo. IN: CASTROGIOVAnNI, A. C. [et. al.] orgs. Movimentos no ensinar Geografia: rompendo rotações. Porto Alegre: Evangraf, 2015. p. 41 - 54.

CAVALCANTI, L. de S. Geografia escolar e procedimentos de ensino numa perspectiva socioconstrutivista. In: Geografia e práticas de ensino. Goiânia: Alternativa, 2002.

CIOCCARI, C. C. Ensino de geografia e o trabalho de campo: construindo possibilidades de ensino e aprendizagem sobre o espaço urbano e rural em Júlio de Castilhos, RS. 2013. 93f. Dissertação (Mestrado em Geografia) - Universidade Federal de Santa Maria, Santa Maria, 2013.

DEMO, P. Saber pensar. 3. ed. São Paulo: Cortez: Instituto Paulo Freire, 2002. 159 p.

FRÉMONT, A. A Região, Espaço Vivido. Coimbra: Almedina, 1976.

FREIRE, Paulo. Pedagogia da autonomia: saberes necessários à prática educativa. São Paulo: Paz e Terra, 1998.

GANDIN, A. B. Metodologia de projetos na sala de aula: relato de uma experiência. São Paulo: Loyola, 2001.

GIL, A. C. Como elaborar projetos de pesquisa. 4. ed. São Paulo: Editora Atlas, 2007.

GONZÁLES, M. S. ¿Qué escuelas de Geografia para educar en ciudadanía?. In: Revista Didáctica de las Ciencias Experimentales y Sociales, n. 24. Valência: Editora da Universidade de Valência, 2010 .

KAERCHER, N. A. A Geografia é o nosso dia-a-dia. In: CASTROGIOVANNI, A. C. et al. (Orgs.) Geografia em sala de aula: Práticas e Reflexões. UFRGS, Porto Alegre/RS, $2^{\circ}$ Ed. 1999. p. 11-21.

KAERCHER, N. A. Desafios e Utopias no Ensino de Geografia. Porto Alegre: UFRGS/AGB, 2003.

LEITE, L. H. A. Pedagogia de projetos e Projetos de Trabalho. Presença Pedagógica, v. 73, p. 6269, 2007.

LOPES, C. S.; PONTUSCHKA, N. N. Estudo do Meio: fundamentos e estratégias. Maringá: Eduem, 2010.

MARCOS, V. de. Trabalho de Campo em Geografia: Reflexões sobre uma Experiência de Pesquisa Participante. Boletim Paulista de Geografia. São Paulo: AGB, n. 84, p. 105 - 136, 2006.

MARTINS, J. S. O trabalho com projetos de pesquisa: do ensino fundamental ao ensino médio. Campinas: Papirus, 2001.

MORO, I. L. Práticas pedagógicas em geografia na perspectiva da pedagogia da alternância. GEOSABERES: Revista de Estudos Geoeducacionais, vol. 7, núm. 13, 2016. 
PAIVA, P. B.; OLIVEIRA, S. R. L. Trabalho de campo e o ensino de geografia nos colégios públicos estaduais de ensino médio em Jataí/GO. In: IX ENCONTRO NACIONAL NEPEG DE FORMAÇÃO DE PROFESSORES. 2018. Caldas Novas (GO). Anais... 19 a 21 de agosto - 2018. Disponível em: http://nepeg.com/forum/ix-forum-nepeg/. Acesso em: 14 de jan. de 2021.

PERRENOUD, P. As competências para ensinar no século XXI: a formação dos professores e o desafio da avaliação. Porto Alegre: Artmed, 2002.

PONTUSCHKA, N. N. Interdisciplinaridade: Aproximações e Fazeres. Terra Livre - AGB, São Paulo, 1999, n. 14, p. 100-102-111, Disponível em: http://www.agb.org.br/files/TL_N14.pdf, acesso em 12 de Nov. de 2020.

PRADO, M. E. B. B. Pedagogia de projetos. Gestão escolar e tecnologias: 2005. Disponível em: http://www.eadconsultoria.com.br/matapoio/biblioteca/textos_pdf/texto18.pdf. Acesso em: 08 de março de 2014.

REGO, N. et al. Geografia e educação: geração de ambiências. Porto Alegre: UFRGS, 2000.

REGO, N. COSTELA, R. Z. EDUCAÇÃO GEOGRÁFICA E ENSINO DE GEOGRAFIA, DISTINÇÕES E RELAÇÕES EM BUSCA DE ESTRANHAMENTOS. Signos geográficos. Goiânia, v.1, P.1-15. 2019.

REGO, T. C. Coleção Memória da Pedagogia. São Paulo: Duetto, Vol. 2, 2005.

REGO, N. Geração de Ambiências: três conceitos articuladores. Educação, Porto Alegre, v. 33, n.1, p. 46-53, jan./abr. 2010. Disponível em: http://revistaseletronicas.pucrs.br/ojs/ index.php/faced/article/view/6780. Acesso em: 13 fev. 2019.

REGO, N. Apresentando um pouco do que sejam ambiências e sua relação com a Geografia e a Educação. In: SUERTEGARAY, D. M. A.; HEIDRICH, A. L. (Org.). Geografia e educação: geração de ambiências. Porto Alegre: Editora da Universidade Federal do Rio Grande do Sul, 2000.

ROHDE, M. D. S. Percepção dos problemas ambientais urbanos a partir do uso de mapas mentais: uma proposta de educação ambiental crítica/emancipatória em escola urbana de Rosário do Sul-RS. 2012. 111f. Dissertação (Mestrado em Geografia) - Universidade Federal de Santa Maria, Santa Maria, 2012.

ROSSATO, M. S.; SUERTEGARAY, D. M. A. A pesquisa no ensino de Geografia como possibilidade de diálogos trans e interdisciplinares. Geografia, Ensino \& Pesquisa, Santa Maria, vol. 18, n. 2, maio/ago. 2014.

SANTANA, A. S. Metodologias para o ensino de geografia na educação de jovens e adultos EJA. 2015. Disponível em: https://eventos.set.edu.br/enfope/article/viewFile/1505/72. Acesso em: 12 de jan. de 2021.

SANTOS, M. A natureza do espaço, técnica e tempo, emoção e razão. São Paulo: HUCITEC, 1996. 
SANTOS, J. de J. Ensino de geografia nos anos iniciais: leitura de mundo através de conceitos e mapas. Poiésis Pedagógica - v. 5/6 - p. 95-112 - jan./dez. - 2007/2008.

SILVA, V. de P. da. O ensino de geografia por meio de projetos de pesquisa: experiências em escolas públicas de Uberlândia - MG. Revista Ensino de Geografia, Uberlândia, v. 2, n. 2, p. 23 38 , jan./jun. 2011.

SOARES, et al. A formação do cidadão no ambiente escolar: da conscientização à intervenção na própria realidade. Monografias ambientais, UFSM, Santa Maria, v(8), $\mathrm{n}^{\mathrm{o}}$ 8, p. 1858 - 1869, AGO, 2012.

SPRINGER, K. S.; SOARES, E. G. A pedagogia de projetos como alternativa metodológica às práticas tradicionais no ensino de geografia. 2008. Disponível em: https://educere.bruc.com.br/arquivo/pdf2008/614_359.pdf. Acesso em: 4 de jan. de 2021.

THIESEN, J. da S. Geografia escolar: dos conceitos essenciais às formas de abordagem no ensino. Geografia, ensino e pesquisa, Santa Maria, v.15, n.1, jan./abr. 2011.

TOLEDO, C. de A. A. de; VIEIRA, P. H. Roteiro para elaboração de projeto de pesquisa. In: TOLEDO, C. de A. A.; GONZAGA, M. T. C. (org.). Metodologia e técnicas de pesquisa: nas áreas de Ciências Humanas. Maringá : Eduem, 2011. p. 21-40. 